\title{
Impact of the Next Generation EU on rural areas: First lessons from the selected national plans
}

\author{
Jorge NÚÑEZ FERRER ${ }^{1}$, Petr BLIŽKOVSKY²
}

${ }^{1}$ CEPS (Centre for European Policy Studies), Brussels, Belgium

${ }^{2}$ Mendel University in Brno, Faculty of Business and Economics

\begin{abstract}
The purpose of the paper is to assess the national plans under the EU's Next Generation EU recovery plan and particularly the Recovery and Resilience Facility. The method is based on a qualitative review of plans of the largest EU member states. The focus is on evaluating the way the rural areas are being targeted by the plans and what instruments are proposed. The research limitations are represented by the lack of details in the plans and the lack of research on the link between the Recovery and Resilience Facility and rural areas. The European Union is facing numerous challenges in a rapidly changing integrated global economy. On the one hand to get the economy in motion after COVID, while on the other aiming to transform the economic system to a more sustainable one, with core objectives including the mitigation of climate change and mainstreaming circular economy. These changes will have substantial repercussions on the economic structures and the economic sectors of the member states, including agriculture. The vision for the rural areas can, however, be a neglected subject. The practical implications of the research are that it can contribute to prepare rural areas to the optimal use of the resources. Social implications of supporting rural areas are the decreasing of disparities within the EU and strengthening of social and economic cohesion.
\end{abstract}

Keywords: Next Generation EU, Recovery and Resilience Facility, rural areas, national plans

\section{Introduction}

Most member states have completed their national recovery and resilience plans (NRRPs) which are being assessed and approved by the European Commission followed by the adoption by the Council of the implementing decisions. Council to be able to draw the support from the Recovery and Resilience Facility (RRF). At the moment of completing this article 18 plans have been approved by the Commission, with sixteen having the implementing decision approved and ready to receive the first financial support.

The RRF instrument is part of the Next Generation EU (NGEU) assistance conceived to help member states overcome the impacts of COVID-19 on their economies. NGEU comes on top of the EU's Multiannual Financial Framework (MFF) for 2021-2027 of the EU budgets. In the final composition of the NGEU only a limited part will directly complement the traditional EU budget policies. The overwhelming share of the funding $(90 \%)$ goes to the RRF, with $€ 672 \mathrm{bn}$ (of which grants are $€ 312.5 \mathrm{bn}$ and loans $€ 360 \mathrm{bn}$ ). Or the remaining $10 \%$, there is a $€ 47.5 \mathrm{bn}$

https://doi.org/10.11118/978-80-7509-820-7-0337 
increase for Cohesion Policy (ReactEU); $€ 5$ bn in grants for research and innovation, funding for debt and equity in the InvestEU financial instruments; $€ 7.5 \mathrm{bn}$ for rural development; $€ 10$ bn for the Just Transition Fund, and $€ 1.9$ bn for the Union's civil protection mechanism. Of course, this percentage shares look a bit different if we only look at the grants, in this case the RRF represents $80 \%$ of the grants.

The NGEU funds, be it for the RRF or the funds complementing existing policies in the EU budget are governed differently to the EU Cohesion policy or agricultural and rural policies, this is due to the particularities of the NGEU as a time limited emergency response fund, raised as an Externally Assigned Revenue under Article 21(2)(a) of the EU's Financial Regulation (Regulation (EU, Euratom) 2018/1046). This regulation imposes a different management system, namely central management rather than shared management, i.e. the European Commission manages and the beneficiary (or interlocutor of the European Commission) is the Central government, not the managing authorities in the regions or paying agencies for rural and agricultural funds. This has a number of implications for the governance of the funds. In addition, while originally the funds directed to expand existing EU programmes were going to have separate regulations, these have been integrated in the ordinary regional, agricultural and environmental regulations.

For the RRF, the governance and implementation rules are significantly different ${ }^{5}$, with important implications in terms of the way those funds will be affecting regions and rural areas. Unfortunately there are very few studies looking at the impact on rural areas of the recovery programme.

A first analysis has been performed by Valenza et al. (2021) who have analysed for the Committee of the Regions how the NRRPs have taken into account regional and local issues and involved the local authorities. The report sees in the RRF a regression from the principle of subsidiarity and an insufficient attention to territorial development. Also a CPRM (2020) report raises serious issues on the lack of involvement of local authorities in the design on the recovery instruments and the centralized nature of the programmes.

This paper gives a short overview on the role of the RRF and the way the NRRPs address specifically the rural dimensions, based on a review of the Spanish, Italian and French programmes undertaken by the authors. The rules of the RRF are presented in the regulation for Recovery and resilience facility ${ }^{6}$ and the guidelines produced by the European Commission ${ }^{7}$ and have been summarised and analysed by Nuñez Ferrer et al. (2021).

\footnotetext{
${ }^{5}$ For more details please refer to Nunez Ferrer J. and F. Corti (2021)

${ }^{6}$ Regulation 2021/241 of the European Parliament and of the Council of 12 February

2021 establishing the Recovery and Resilience Facility, OJ L 57, 18.2.2021, p. 17-75

7 All guidelines are published at https://ec.europa.eu/info/business-economyeuro/recovery-coronavirus/recovery-and-resilience-facility_en
} 


\section{Review on the role of the RRF and its impact on rural areas}

The role of the RRF is multiple and complex. Officially, based on the regulation establishing the facility, the objective is to counter the impact of the COVID pandemic. However, the recovery package does not aim to bring the economy back to the situation before the pandemic, but to redirect the economy based on the Green Deal objectives and a recognition that some of the most affected countries already needed considerable structural reforms and were not recovering from the financial crisis a decade ago. The aim is thus to direct the economies towards cleaner, more circular, digital, and more just economic structures aligned with the climate objectives. This is also the reason for the additional 'resilience' objective in the name.

The main requirements based on the regulation and guidelines of the recovery and resilience facility are (from Núñez Ferrer, 2021):

\section{a) Requirements}

- to contribute to the seven European Flagships: 1) Power up, 2) Renovate, 3) Recharge and Refuel, 4) Connect, 5) Modernise, 6) Scale-up and 7) Reskill and upskill

- to allocate $37 \%$ of the RFF funding to climate investment based on the methodology for climate tracking

- to dedicate $20 \%$ of the funding to the digital transition based on the methodology for digital tagging

- to contribute to the strategic autonomy of the Union

- to explain how the plans mainstream gender equality and equal opportunities for all

\section{b) Macroeconomic and reform requirements}

- to ensure consistency with the Country Specific Recommendations (CSR) to the member states emerging from the European semester

- to introduce reforms geared to improving conditions for the business sector

- to introduce reforms to improve the quality of public administration

- to adopt more efficient public investment processes, including expanding the effective use of public-private partnerships

- to introduce measures to avoid aggressive tax planning that distorts competition between firms.

\section{c) Overarching new environmental conditions}

- to ensure that the programmes 'do no significant harm' to any of the six environmental objectives as defined in Article 17 of the EU Taxonomy Regulation.

These represent a large number of objectives going well beyond the traditional EU funds and give member states extraordinary leeway on the areas to spend the money. 
In addition, a particularity of this support is that the support does not need national co-finance.

However, there are strict conditionalities attached to the use of the RRF. The guidelines require that $37 \%$ of the funds are spent in investments addressing climate and $20 \%$ to digitalisation. It also requires that the macroeconomic recommendations in the Country Specific Recommendations (CSRs) of the European Semester are addressed.

The RRF is thus not directly or necessarily addressed to territorial imbalances and this has been deplored by Valenza et al. (2021), but it is important to understand that the RRF does not need to address every problem of the economy in every sector. The RRF is additional to the normal EU budget policies, the national budgets and also the additional support by NGEU to regions (REACT-EU) and rural development.

Nevertheless, the priorities of the RRF and the focus of the funds will have an impact on the development of the rural areas, their sustainability and future viability. This is because the RRF will be a major investment tool and the choices may affect the rural areas considerably. In the following areas of investment and reforms the RRF can have a major impact on the rural areas: transport, digitalisation, education, and administrative and judicial services. The way rural areas will the connected to the rest of the economy and the opportunities the funds may develop for the citizens of those areas will impact their future.

In the area of digitalisation several countries trail behind, and the most affected areas are always rural. In the digital scoreboard by the European Commission the very different coverage between member states is clear.

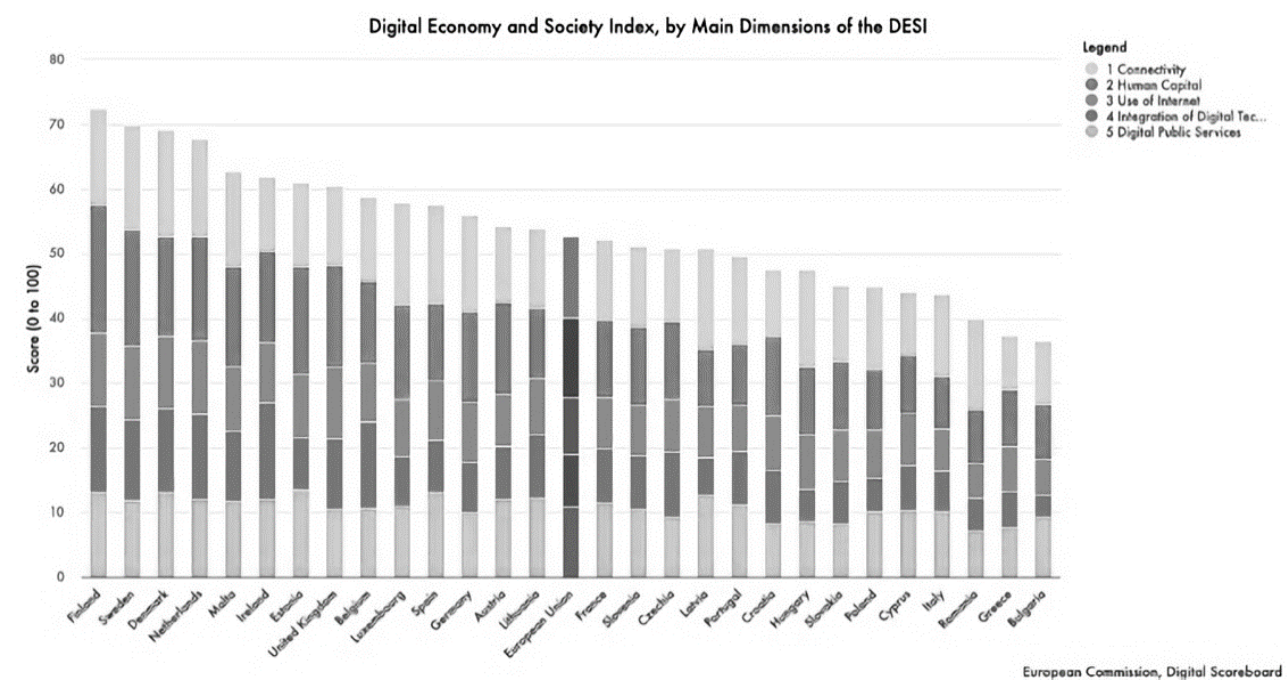

Figure 1. Digital scoreboard index

Source: Extracted from, European Commission, Digital Scoreboard https://digital-agenda-data.eu 
Another telling graph on the situation in rural areas, is the unemployment level. For many countries, and in particular poorer countries the unemployment level in rural areas is particularly high. It is interesting to note that in some countries, the worse situation is urban, but this is also the result to migration out of the rural areas in the last years, as the rural areas lost services and opportunities during the financial crisis. The impact of the financial crisis for rural areas has been described by SánchezZamora and Gallardo-Cobos (2020). The study shows how economic disparities between regions, urban and rural and even rural to rural regions have increased.

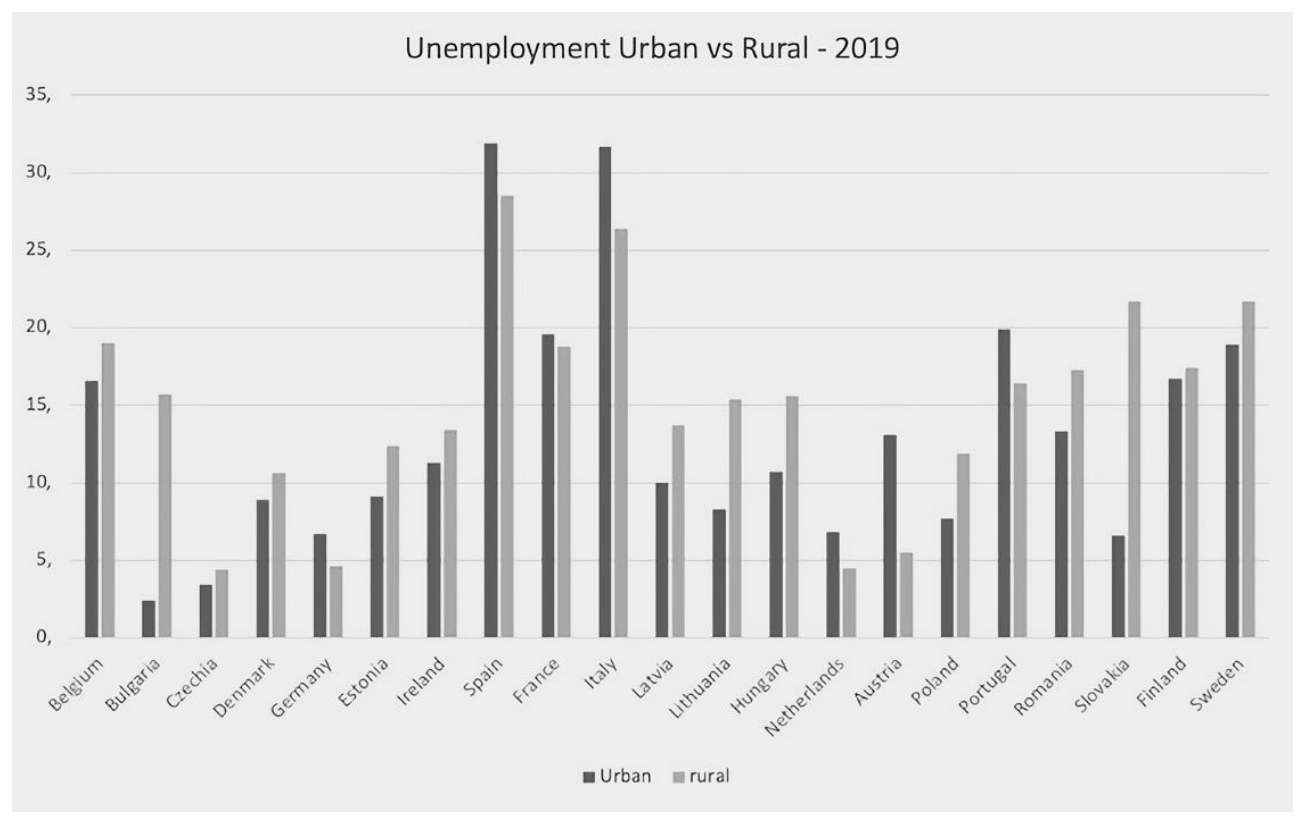

Figure 2. Urban and rural unemployment in the $E U$

Source: Eurostat data.

A large recovery programme aiming at sustainability and reducing the impact of the financial crisis as well as COVID would be expected to show a particular sensitivity on how the actions affect territorial cohesion between and within regions. How the RRF will focus on rural areas is thus important. We have reviewed programmes by main beneficiaries of the funds to understand how the countries addressed rural areas, namely in Spain, Italy and France.

From the analysis by Valenza et al (2021) several countries have not addressed sufficiently the challenges for regions and rural areas. Their analysis has led to an index presenting an estimated level of involvement of local and regional authorities (LRAs) in the drafting of the RRF. This varies across the countries, but shows that the countries with the largest financial support are those with the lowest participation in the sample of countries reviewed. 


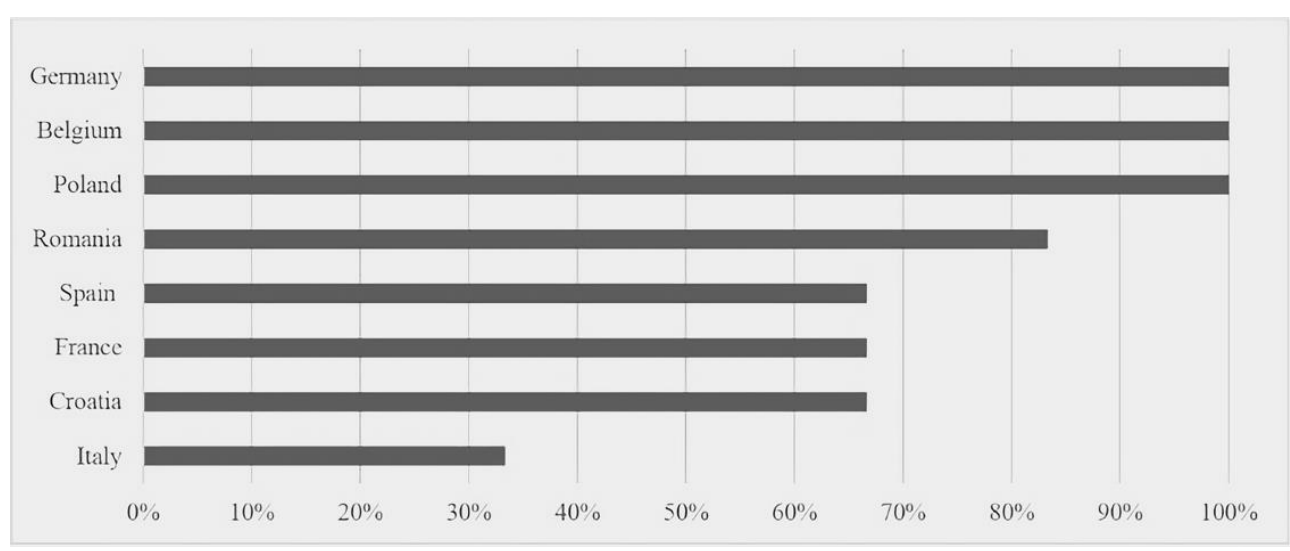

Figure 3. Involvement of the LRAs in the preparation of the NRRPs

Source: Valenza et al. (2021)

Also the role of the LRAs in implementing and monitoring and evaluating the RRF is very different across the countries. Their role in the implementation is generally high, because many regional offices are responsible to implement many national policies and EU programmes, the same ones will be used for the RRF.

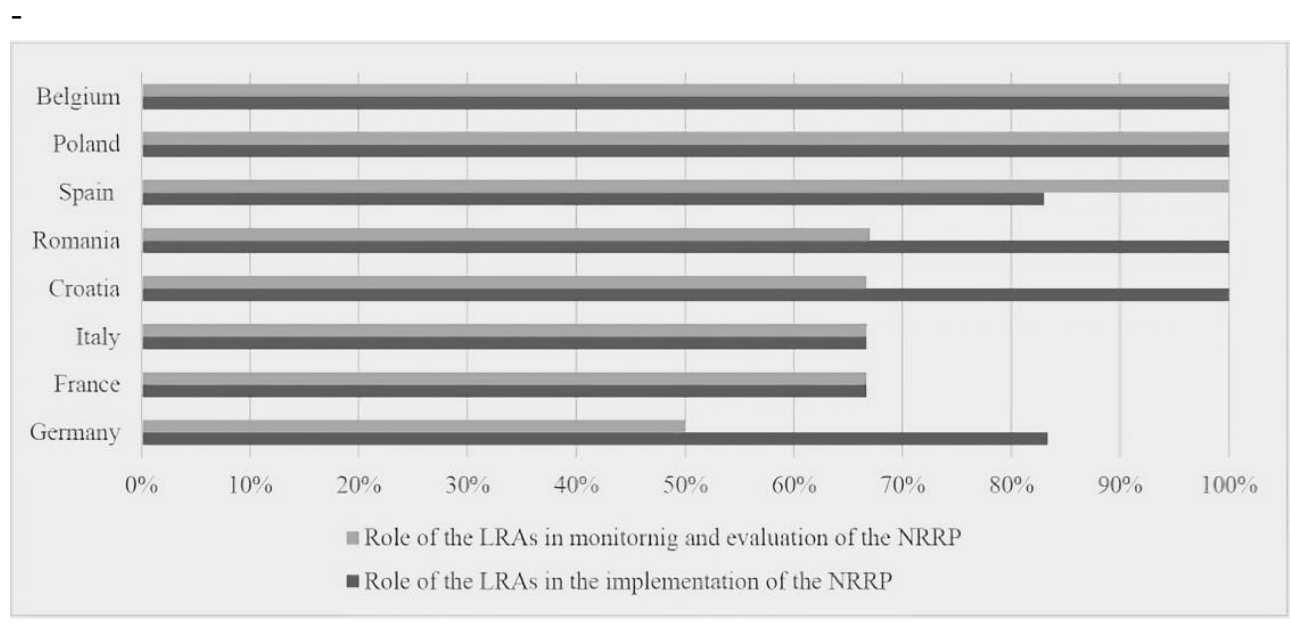

Figure 4. Role of the LRAs in implementation, monitoring and evaluation

Source: Valenza et al. (2021) 


\section{The presence of rural development problems in the NRRPs}

As mentioned above the rural areas are generally not addressed with specific measures explicitly targeting them, but will be affected by the priorities the programmes put in developing infrastructures, such as for transport, digitisation and also in the investments in education, training and coverage of essential services (justice, health, policy etc.). This section checks the Spanish, Italian and French programmes for such aspects.

\section{The Spanish National Recovery Plan and rural areas}

The Spanish programme ${ }^{8}$ is notable for the sheer number of measures covering many social, economic and environmental issues. Amongst those objectives, the plan claims to have 130 measures affecting rural areas. However, many of those are nationwide measures that are relevant in the sense that these also impact rural areas. One of the core concerns expressed in the programme is rural depopulation, and Spain has one of the worst declines in rural population in Europe as indicated in ESPON (2020). The plans aim to reverse the trend by increasing the quality of services and infrastructures in the rural areas, in particular education and digital infrastructures, such as broadband access.

More specifically, it is in component number 3 ("Environmental and digital transformation of the agri-food and fisheries system") of the national plan, where the measures directly affecting rural areas are included. This will take place through the 'Strategy for the Digitisation of the Agri-Food and Forestry Sector and the Rural Environment: development of actions to support the digitalisation and entrepreneurship of the agri-food and forestry sector and the rural environment'. The objectives and the completion date of the measures (reforms and investments) are coherent, and this is an ambitious measure, as it consists of proposing a second action plan, for the correct adoption of the Spanish Strategy for the Digitalisation of the Agri-food and Rural Areas, adopted by the Spanish government in March 2019.

Going into more detail, in order to tackle rural problems, the Spanish government proposes what it calls 'tractor projects', which include the creation of innovation centres in rural areas and the promotion of local entrepreneurship (Belinchón, F., 2021). In turn, digitisation will play an essential role, as the Spanish government's goal is for $100 \%$ of the national population to have 100 Mbps coverage by 2025 , which directly affects rural areas.

Emphasis is placed on investments in innovation hubs for agriculture and support to precision agriculture. However, the are several measures where the budgetary part devoted to rural policy is not specified. The national plan contains also funds on softer measures which may impact rural areas and have to be further assessed. On

${ }^{8}$ Gobierno de España (2021), Plan de Recuperación, Transformación y Resiliencia España Puede 
measures to improve access to public services, the plan wishes to assist less populated areas, but the administrative reforms often will not allocate funding from the RRF, thus it is unclear what the budget will actually be.

It is interesting that the Spanish plan considers local actors essential for the adoption of measures in rural areas, also seeking that member of the public and private sectors act jointly, in order to increase the efficiency of the measures adopted (Asenador, S. H., 2021).

Overall, the measures proposed by the Spanish government are encouraging, but their success or failure depends on the correct adoption of measures and the existence of good governance both at the national and local level.

\section{The Italian National Recovery Plan and rural areas}

The Italian NRRP 9 announces specific actions to promote sustainable agriculture and circular economy, complementing the EU budget and RRF additional Rural Development assistance. The plan makes also concrete reference on the fourth pillar ("territorial and social cohesion").

There is also considerable emphasis on technical assistance for local authorities which could help rural areas. Amongst the instruments we can find:

- One of the first objectives is to improve connectivity in rural areas.

- Other missions address directly rural areas problem with concrete investments (i.e. Investment for green communities).

- $\quad$ Regarding circular economy, in addition to the Italian 'Circular Economy Package' the PNRR aims to fill the structural gaps that hinder the development of the sector.

- Support to value chains to develop a more sustainable food sector.

- Support to develop of the logistics for agricultural sector.

- Introducing renewable energy and energy efficiency infrastructures in agricultural buildings.

- Integrated projects combining circularity, mobility, and renewables (Green islands).

- Support for the development of precision agriculture.

However, contrary to the more spread distribution of the funds in the Spanish Programme, the Italian programme has a clear focus on key infrastructures, such as rail transport. Less emphasis is placed on supporting smaller actors.

Nevertheless there are specific actions envisaged. The Italian plan addresses indirectly rural issues, for example through the component called "culture and tourism 4.0". Although there is no direct mention of the effects that the reforms proposed by the plan will have on rural areas, a series of investments are foreseen that will affect them. Specifically, through the investment for the systematic enhancement process for historical rural buildings (of private individuals or third

\footnotetext{
${ }^{9}$ Republica Italiana (2021), Piano Nazionale de Ripresa e Resilienza
} 
sector entities) and landscape protection. These measures are expected to have a direct effect on local economies and aim promote sustainable tourism in rural areas by: a) offering programs to enhance the identity of historic parks and gardens, with a contribution to improving the quality of life; leveraging cultural heritage; and promoting a vast regeneration action of historic parks and gardens. In turn, the component called 'Sustainable agriculture and circular economy' also aims, to support the sustainable and resilient development of rural and mountain areas, to influence the development of rural areas.

In addition, the digital transformation, which includes the modernisation of agricultural machinery, among other areas of investment, could have an effect on rural areas, since, as mentioned by Moreschi (2021), there is an increasing connection between cultural heritage, tourism, and agricultural production.

Finally, making an overall assessment, it can be said that the Italian plan does, despite its emphasis on large infrastructures, take into account the needs of rural areas. However, the fact that most of the reforms in the plan are not directly focusing on rural areas make it difficult to measure to what extent these will actually benefit.

\section{The French National Recovery Plan and rural areas}

The measures in France ${ }^{10}$ are more limited, also because the RRF funds are smaller. The programme focuses on the green transition and has a number of measures that are relevant to rural areas. There is a commitment to green infrastructure and mobility investments in rail connections, although the rural dimension is not clear.

For energy, rural electrification is presented as a key objective. The investment programme number 7 of component 3 called "Strengthening the resilience of electricity networks and energy transition in rural areas" addresses the French rural needs.

The plan calls for an energy transition in the rural areas by building the necessary renewable energy infrastructures. France also proposes to invest in the supply network to and cut the power shortages which some parts of France suffer.

Another priority clearly addressed at rural areas is the investment in the connectivity networks to improve the conditions for companies and citizens and make the areas more attractive.

What is clear is that France is not considering the RRF funding as having any large role to address the situation in the rural areas. That said France has its own national recovery support of $€ 100$ billion "France Relance" 11 launched for 2020 to 2022 which includes a considerable number of funds dedicated to improve access to services in local areas, including rural.

\footnotetext{
${ }^{10}$ Gouvernement Français (2021), Plan National de Rélance et Résilience 2021, available at https://www.economie.gouv.fr/files/files/directions_services/plan-derelance/PNRR\%20Francais.pdf

${ }^{11} \mathrm{https} / / / \mathrm{www}$. gouvernement.fr/les-priorites/france-relance
} 


\section{Conclusions}

The RRF is not conceived to address specifically rural areas. Nevertheless, many rural areas as suffering from a socio-economic decline and an exodus of the population. The impacts of these changes need to be managed if not by the RRF, by other national and EU programmes. The RRF, however, can have considerable impacts on rural areas depending on how the government handles the development of cross-national infrastructures and their link to the rural areas. The impact to the rural areas of EU and national interventions requires an analysis on the level of additionality the RRF creates above other public funding and understand the combined impacts with a clear view on the objectives for these areas. Where the attention should lie, is on the actual investments in infrastructures that can offer a lifeline for the rural economy, and this is in digitisation, education, access to services and transport, other support has already dedicated funding from other sources. All the RRF programmes reviewed mention the rural areas, but the de-facto support needs to be monitored and the link and complementarity with other programmes guaranteed.

\section{References}

1. Consejo Económico y Social España (2021), "Un medio rural vivo y sostenible", Informe 02/2021, pp. 171-230. Available at: http://www.ces.es/documents/10180/5250220/Inf0221.pdf

2. ESPON (2020), Shrinking rural regions in Europe - Towards smart and innovative approaches to regional development challenges in depopulating rural regions, Policy Brief, ESPON.

3. Gouvernement Francais (2021), Plan National de Rélance et Résilience 2021

4. Molica F. and E. Leal Fontas (2020), "Next Generation EU": a threat to Cohesion Policy?, CPMR Technical note, December 2020.

5. Núñez Ferrer J. (2021), 'Avoiding the Main Risks in the Recovery Plans of Member States', Recovery and Resilience Reflection Paper No 1, CEPS, March 2021.

6. Núñez Ferrer, J., Corti, F. (2021), Assesing reforms in the national recovery and resilience plans- Italy, CEPS Research Report, No. 3/2021, June.

7. Núñez Ferrer J., F. Corti, C. Alcidi, A. Paz Otero (2021), 'Steering and Monitoring the Recovery and Resilience Plans - Reading between the lines', Recovery and Resilience Reflection Paper No 2., CEPS, May 2021.

8. Sánchez-Zamora, P.; Gallardo-Cobos, R. Territorial Cohesion in Rural Areas: An Analysis of Determinants in the Post-Economic Crisis Context. Sustainability 2020, 12, 3816

9. Valenza A., A Iacob, A. Clarissa, P. Celotti, S. Zillmer and J Kotrasinski (2021), "Regional and local authorities and the National Recovery and Resilience Plans", Report for Committee of the Regions.

10. Belinchón, F. (2021), "El plan de España para evitar la despoblación rural”, El país. Available https://cincodias.elpais.com/cincodias/2021/04/16/economia/1618585617_484935.htm 
11. Asenador, S. H., (2021), "El Gobierno destinará 10.000 millones de los fondos europeos al reto de dinamizar la España rural", Expansión. Available at: https://www.expansion.com/economia/2021/05/22/60a8d49d468aeb1b1c8b457e.html

12. Moreschi, F. (2021), "Il Piano nazionale di ripresa e resilienza vede protagonisti agricoltora e digitalizazzione", Teatro Naturale. Available at: https://www.teatronaturale.it/strettamente-tecnico/legislazione/35908-il-pianonazionale-di-ripresa-e-resilienza-vede-protagonisti-agricoltura-e-digitalizzazione.htm 